\title{
Association between knee, ankle, and hip joint angles and contact time during the lunge and recoil phases among sabreurs \\ Asociación entre los ángulos articulares de la cadera, rodilla y tobillo con el tiempo de contacto durante el fondo y el recobro en sablistas \\ *Álvaro Segueida Lorca, **Fernando Maureira Cid, ***Pablo Valdés Badilla, ****Emerson Franchini, *Tomás Herrera \\ Valenzuela \\ *Universidad Santo Tomás (Chile), **Universidad Católica Silva Henríquez (Chile), ***Universidad Autónoma de Chile (Chile), ****Universidade de Sao Paulo (Brasil)
}

\begin{abstract}
Background: Fencing is an Olympic combat sport divided into three different disciplines: the foil, the épée and the sabre. The most used attack movement by fencing athletes is the lunge. Problem and Aim: The main objective of this study was to correlate joint positions of the lower limb with the contact time of the lunge attack followed by the recoil. Methods: Ten male (mean $\pm \mathrm{SD}$, age $=22.0$ \pm 5.7 years; body mass $=70.3 \pm 11.1 \mathrm{~kg}$; height $=174.6 \pm 9.4 \mathrm{~cm}$ ) fencing athletes (sabre) from national and international teams participated. Results: We observed a correlation between the contact time of the lunge attack and hip angle $(\mathrm{r}=-.75, p=<.05)$. Conclusions: The degree of flexing of the hip joint, evaluated through video, was inversely related to the contact time in the lunge attack and recoil in male sabre athletes.
\end{abstract}

Key words: Sports, combat sports, conditioning, lunge, fencing.

Resumen. Antecedentes: La esgrima es un deporte de combate olímpico dividido en tres diferentes armas: florete, espada y sable. El movimiento de ataque más utilizado por los esgrimistas es el fondo. Problema y objetivo: El principal objetivo de este estudio fue correlacionar las posiciones articulares de las piernas con el tiempo de contacto del fondo seguido por el recobro. Métodos: Diez esgrimistas (sable) masculinos (media \pm DS, edad $=22.0 \pm 5.7$ años; peso corporal $=70.3 \pm 11.1 \mathrm{~kg}$; talla $=174.6 \pm 9.4 \mathrm{~cm}$ ) de equipos nacionales e internacionales participaron. Resultados: Observamos una correlación entre el tiempo de contacto del ataque de fondo y el ángulo de la articulación de la cadera $(\mathrm{r}=-.75, p=<.05)$. Conclusiones: El grado de flexión de la articulación de la cadera evaluado a través de video, estuvo inversamente correlacionado con el tiempo de contacto en el ataque de fondo y el recobro en sablistas masculinos.

Palabras clave: Deportes, deporte de combate, acondicionamiento, fondo, esgrima.

\section{Introduction}

Fencing is an Olympic combat sport divided into three different techniques, each with their own weapon: the foil, the épée and the sabre. The most used attack movement by fencing athletes is the lunge (Gutiérrez, Rojas, Antonio \& Navarro, 2013). Therefore, this is the most investigated technical gesture in fencing (Cronin, McNair \& Marshall, 2003; Gutiérrez et al. 2013; Gutiérrez, Zingsem, Gutiérrez, Giles \& Rojas, 2014; Greenhalgh, Bottoms \& Sinclair, 2012). Lunge performance is influenced by lower body muscle power, body mass, flexibility and leg length (Cronin et al. 2003), coordination (Gutiérrez et al. 2013) and situations of uncertainty (Gutiérrez et al. 2014)

On the other hand, when a lunge action is carried out and the objective of touching the opponent is not achieved, it is necessary to perform a change of direction or a retreating action to avoid the opponent's touch. This action (change of direction) is the second most common action made by sabreurs (Aquili, Tancredi, Triossi, De Sanctis, Padua, D'Arcangelo \& Melchiorri, 2013).

Speed and the change of direction seem to be determining factors in fencing performance, which are supported by lower body muscle strength and power (Turner et al. 2014). As mentioned earlier, the gestures of lunge and retreat in fencing have been widely studied and related to various performance factors. As it has been demonstrated in other sports (especially in the sprint) (Haugen, Tonnesen \& Seiler, 2015),

Fecha recepción: 21-10-19. Fecha de aceptación: 11-03-20

Álvaro Segueida Lorca

asegueida@gmail.com there is a clear relationship between the increase in the speed of sports actions and the decrease in the times of application of force on the floor that affects in the degree of flexion of the knees.

In addition, many sports involve movements that require generation of force over a short period of time (McBride, Triplett, Davie \& Newton, 1999), for example, in the case of sprint performance along with the speed increase, the groundcontact time typically decreases (Haugen et al. 2015) and there is evidence that higher level athletes of a combat sport present lower contact time compared to lower level athletes when executing different vertical jumping tasks (Zaggelidis, Lazaridis, Malkogiorgos \& Mavrovouniotis, 2012). Along with this, certain joint angles of the body are more favorable for the development of muscle power (Garhammer, 1993).

In fencing, the closest approach to the control of contact times on the ground is the assessment of the reactive strength index (RSI) through its components, such as flight time and contact time. Indeed, better RSI have been observed in elite fencers compared to sub-elite ones of the Greek national team (1.48 v/s 1.38, respectively) (Tsolakis \& Vagenas, 2010a). Additionally, RSI has been correlated with lunge time ( $\mathrm{r}=$ $.41)$ and shuttle test scores ( $\mathrm{r}=-.44)$ (Tsolakis, Kostaki \& Vagenas, 2010b); lunge distance $(\mathrm{r}=.38)$ and change of direction speed ( $\mathrm{r}=-.41)$ (CODS) (Turner, Bishop, Chavda, Edwards, Brazier \& Kilduf, 2016a); countermovement jump $(\mathrm{CMJ})(\mathrm{r}=.75)$, single-leg jump front foot (SLJFr) $(\mathrm{r}=.79)$, single-leg jump back foot (SLJBk) (r=.70), standing broad jump (SBJ) $(\mathrm{r}=.61)$, speed forward (SPDFwd) $(\mathrm{r}=-.45)$, speed back $(\mathrm{SPDBk})(\mathrm{r}=-.59)$ and repeat lunge ability $(\mathrm{RLA})(\mathrm{r}=-.53)$ (Turner et al. 2016b).

Moreover, the joint angles of body segments or some 
specific gestures seen during fencing have also been used to study their performances. Sinclair \& Bottoms (2013) studied kinematic differences between male and female fencers and the authors reported no differences in back leg kinematics between genders; in other cases, kinematic differences between elite fencers $\left(\right.$ hip flexion $=$ mean $53^{\circ}$ ) compared to novice $\left(\right.$ hip flexion $=$ mean $40^{\circ}$ ) have been shown (Gholipour, Tabrizi \& Farahmand, 2008). Bottoms, Greenhalgh \& Sinclair (2013) set regressions between rear extremity's knee range of motion in the sagittal plane with sword velocity $\left(\mathrm{R}^{2}=.36\right.$, $p<.01$ ), peak hip flexion of the rear extremity's hip in the sagittal plane with sword velocity $\left(\mathrm{R}^{2}=.24, p<.01\right)$, and peak flexion of the fore extremity's hip in the sagittal plane with sword velocity $\left(\mathrm{R}^{2}=.14, p<.05\right)$. Steward \& Kopetka (2005) reported that lunge velocity was significantly correlated to the time to peak angular velocity of the trailing knee $(p=.022)$ and leading elbow $(p=.047)$. Gresham-Fieguel, House \& Zupan (2008) reported higher magnitudes of peak and average power and average velocity of lunging with the placement of the rear foot perpendicular to the alignment of the forefoot.

However, although lunge and retreat gestures are actions executed at high speed and have been widely studied, to date and to our knowledge, there is no clarity about the relationship between the angles of the lower limbs and the contact time in these actions in sabreurs. Therefore, the main objective of this study was to explore the level of correlation of the joint angles of the lower limbs with the contact time of the lunge attack followed by the recoil evaluated in a novel and low-cost way. Thus, we hypothesized a negative correlation between joint degree and contact time in the lunge and recoil.

\section{Material and Methods}

\section{Participants}

Ten male fencing (sabre) athletes from national $(n=4)$ and international $(\mathrm{n}=6)$ levels (mean $\pm \mathrm{SD}$, age $=22.0 \pm 5.7$ years; body mass $=70.3 \pm 11.1 \mathrm{~kg}$; height $=174.6 \pm 9.4 \mathrm{~cm}$; body mass index $=22.9 \pm 1.7 \mathrm{~kg} / \mathrm{m}^{2}$ ) participated in the present study. Athletes had at least six years of training (4 times per week, 60-120 minutes per session) and had been competing for at least five years. All of them of legal age. All athletes were evaluated during the competitive period and none presented musculoskeletal injuries at the time of data collection. All participants gave their written informed consent before undergoing this study, which was approved by the local Ethical Committee in compliance with the Declaration of Helsinki.

\section{Materials}

A 240-Hz high-speed video camera (HSC) (Casio Exilim ExZR 400) positioned $2.5 \mathrm{~m}$ in the sagittal plane of the sabreurs was used to record the contact times and the angle of the joints of the lower limbs of the front foot during the lunge and recoil. In order to record the movement angles, each participant was assigned reflective points with anatomical markers following, in part, the model suggested by Capozzo, Catani, Croce \& Leardini (1995), as indicated below: first head of the metatarsus, medial malleolus, medial epicondyle, center of the femoral head and acromial process of the scapula.
Each anatomical point was identified by means of palpation. To identify the acromion, the spine of the scapula until reaching the acromion was identified, this point is the beginning of the lateral edge; the most lateral and superior parts were marked with a pencil. The greater trochanter was identified by touching the lateral area of the gluteal muscles with the hand. The evaluator positioned behind the athlete, exerted pressure with the hand and marked the lateral surface of the trochanter with a pencil. The medial epicondyle of the femur was identified with the athlete seated, the evaluator determined the space between the medial femoral condyle and the medial tibial condyle, marking the medial upper border of the tibia with a pencil. For the medial malleolus of the ankle, the athlete was seated. The evaluator palpated and marked the most protuberant area of the medial malleolus with a pencil. The first metatarsus of the foot was also identified with the athlete seated and the most protuberant area of the head of the first metatarsus was marked. All the marked anatomical points correspond to the athlete's dominant side. After marking the anatomical points, reflective markers were placed on athletes by means of double contact tape. For the measurement of joint angles and the contact time, the open access software Kinovea (www.kinovea.org) version 0.8.21 was used.

\section{Procedures}

Three minutes after a standardized 15-minute warm-up, subjects were instructed to place themselves in their usual on guard position with their personal weapon in front of a plastron. They were instructed to leave enough space to perform a lunge attack from the on guard position followed immediately by a recoil action as quickly as possible. After 3 familiarization actions, with recoveries of 2 minutes between them, the athletes could adjust their individual distance for a better execution of the lunge attack. After adjustment, they were asked to perform the attack 3 times each, at the fastest possible speed, with three minutes of rest between attempts to ensure recovery between efforts and the fastest one was used for analysis (Figures 1 and 2).

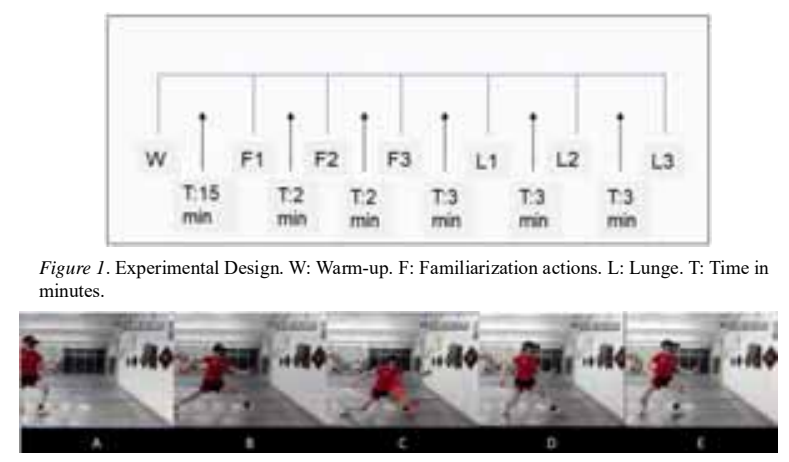

Figure 2. Lunge from the starting to the recoil position. (A-E) (left to right).

For analysis, contact time was measured using Kinovea (www.kinovea.org) version 0.8.21 through frame count and was considered as the time that elapsed from the moment that any area of the front foot touched the surface until any area of the foot ceased to touch. The joint angle that was used was measured when the subjects touched the plastron and began the recoil and was also done using the Kinovea software. We measured: ankle angle formed between the first 
metatarsal head and medial epicondyle of the front foot, knee angle formed by medial malleolus and center of the femoral head of the front foot, and hip angle formed between medial malleolus of the front foot and acromial process of the scapula of the armed arm (Figure 3).

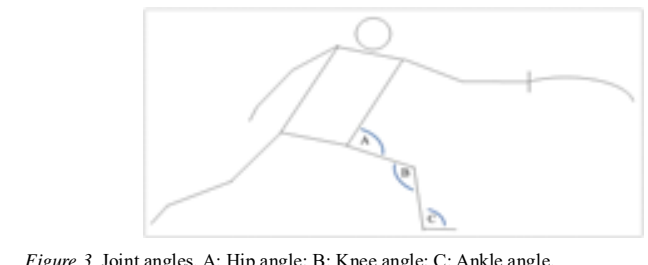

The validity and reliability of the HSC-Kinovea system for the evaluation of times in sports gestures (Balsalobre, Tejero, del Campo \& Bavaresco, 2014) and leg angles during running (Damsted, Nielsen \& Larsen, 2015) have been previously reported.

\section{Statistical Analysis}

The Statistical Package for Social Science software (SPSS, version 22.0, United States of America) program was used. We used the Kolmogorov-Smirnov test to check the normality. To determine the reliability of each assessment, single measures intraclass correlation between trials were conducted. For descriptive purposes, we calculated the mean and standard deviation for each variable. We calculated Pearson's correlation coefficients, with $\alpha$ level of $p \leq .05$ for statistical significance and confidence intervals (95\%) for each significant correlation.

\section{Results}

All data were normally distributed and intraclass correlations demonstrated a high level of reliability between trials of Contact Time $(\mathrm{r}=.956 ; p=.000)$, Hip Angle $(\mathrm{r}=.862$; $p=.000)$, Knee Angle $(\mathrm{r}=.955 ; p=.000)$, Ankle Angle $(\mathrm{r}=.895$; $p=.000)$.

Joint angles and contact time during the lunge and recoil phase are shown in Table 1. The results show that the angle formed in the ankle joint during the lunge and recoil in the sagittal plane and the contact time have a negative no significant correlation $(\mathrm{r}=-.34 ; p=.34)$; the angle of the hip and ankle joint formed during the lunge and recoil in the

Table 1.

\begin{tabular}{ccc}
\multicolumn{3}{c}{ Descriptive information on the measured variables } \\
\hline & Mean \pm SD & $\mathbf{9 5 \%}$ CI \\
\hline Contact Time (ms) & $473 \pm 67$ & $424-521$ \\
Ankle $\left({ }^{\circ}\right)$ & $115.2 \pm 5.51$ & $111.3-119.1$ \\
Knee $\left({ }^{\circ}\right)$ & $104.3 \pm 8.71$ & $98.07-110.5$ \\
Hip $\left({ }^{\circ}\right)$ & $68.4 \pm 6.45$ & $63.79-73.01$ \\
\hline $\mathrm{CI}=$ confidence interval. &
\end{tabular}
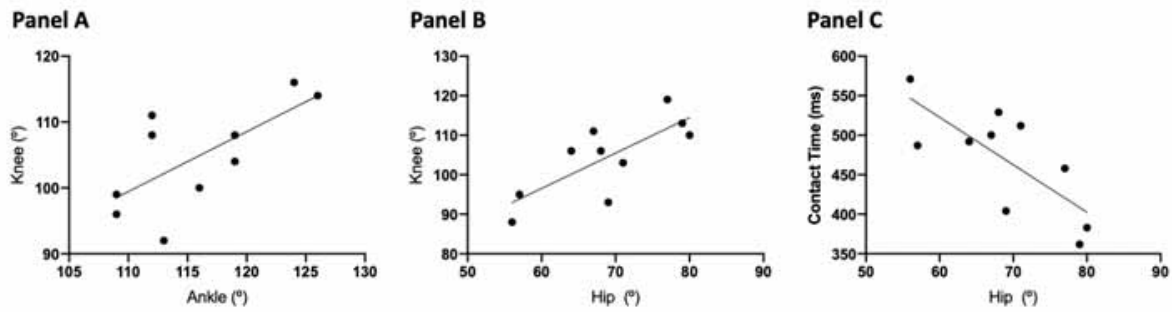

Figure 4. Correlations between ankle, knee and hip joint angle variations and contact time during the lunge and recoil actions in fencers. sagittal plane have a positive no significant correlation $(r=.36$; $p=.31$ ) and the angle formed in the knee joint during the lunge and recoil in the sagittal plane with the contact time have a negative no significant correlation $(\mathrm{r}=-.49 ; p=.15)$.

Figure 4 shows the significant correlation between the measured variables. Panel A shows the correlation between ankle angle and knee angle $(\mathrm{r}=.684 ; 95 \%$ confidence interval $=.0948$ to $.918 ; p=.029)$; Panel B shows the correlation between hip angle and knee angle ( $\mathrm{r}=.768 ; 95 \%$ confidence interval $=.2677$ to $.9421 ; p=.01$ ); Panel $\mathrm{C}$ shows the correlation between hip angle and contact time during lunge and recoil $(\mathrm{r}=-.747 ; 95 \%$ confidence interval $=-.9363$ to $-.2218 ; p=.013)$.

\section{Discussion}

We hypothesized that the lunge attack contact time would correlate with the ankle, knee and hip angles, but we found a significant negative correlation only between contact time and hip angle.

With respect to lunge contact times, the results can be explained in part by the technical action itself. The attack consists of the projection of the armed arm followed by a coordinated drive of the back leg, which, with its extension, quickly gains ground with the front leg. After the flight phase, the foot touches the ground again and the knee is flexed forming a right angle between the leg and the thigh (Iglesias, 1997). Thus, the front foot reaches the ground first with the heel (López, 2008), to then support the sole and finally reverse this sequence to carry out the recoil.

In relation to the joint angles in the final lunge position, the joints of the lower limbs flex. In the case of the knee joint, Iglesias (1997) points out that when the front foot makes contact with the floor, the thigh and the leg form a right angle. Also, Clery (1965) indicates that the front knee will fall vertical from the heel. On the other hand, the advancement of the trunk is the correct position to begin a new technique (Clery, 1965; Thirioux, 1970; Szabó, 1977; Gaugler, 1992). This advancement of the trunk causes a decrease in the joint angle formed with the thigh, which could justify the inverse correlation between the hip angle and the contact time in the lunge (Clery, 1965).

Regarding the correlation found between the hip and knee joints, it could be explained by the kinetic chain phenomenon, which, in the specific case of the lunge, corresponds to a thrust (López, 2008), where, after a rapid extension of the posterior knee (Clery, 1965; Thirioux, 1970) a large acceleration is printed horizontally to the body's center of mass, and the athlete must brake it by touching the ground with their front leg, continue with the movement and begin to retreat. In this sequence of actions, the knee has high demand, which is in accordance with the work of Lee, Kwon, Son, Kang, Kim \& Hyun-Nam (2013) which states that a closed kinetic chain exercise requires greater eccentric strength of the knee extensors for the control of movement 
compared to an open kinetic chain exercise. Therefore, the joint angle reached in the hip joint will directly affect the angle of the knee.

Lunge and retreat actions could also be considered as a change of direction (COD). In this sense, it has been previously shown that high levels of eccentric strength are needed to decelerate the human body from high movement velocities to rapid COD movements (Kovacs, Roetert \& Ellenbecker, 2008); therefore, eccentric muscle strength is necessary to tolerate braking loads or braking capacity to optimize COD performance (Chaabene, Prieske, Negra $\&$ Granacher, 2018). However, predicting COD performance based on measurements in concentric regimes of strength and power appear to be reduced (Chaabene, 2017), which is why Brughelli, Cronin, Levin \& Chaouachi (2008) claimed that jumps that combine both horizontal and vertical ground reaction force appear to predict better COD performance. Turner et al. (2016a) reported that one of the best predictors of change of direction speed (CODS) in fencers was the standing broad jump (SBJ) $(\mathrm{r}=-.65 ; p=<.001)$.

The lunge attack could be considered an axial load or a closed kinetic chain action. Biomechanically, the function of each segment of the body is considered in relation to other interconnected segments (Kim, Kong \& Yoo, 2017), where the movement of one part affects the other (Khademi \& Berenji, 2014), and that in these actions the most complex intramuscular and intermuscular coordination of agonist and antagonist groups are included (Stensdotter, Hodges, Mellor, Sundelin \& Häger-Ross, 2003). This also explains the relationship found between the knee and ankle joints, which, when supporting the foot during the lunge attack, they tend to flex when the extension chain is requested eccentrically at the anterior level of the thigh through the thigh, the kneecap and the quadriceps tendon; at the posterior level of the leg through the soleus tendon; and at the lower level of the foot through the flexor digitorum brevis (Busquet, 2004).

The lunge is a technical action that requires high speeds for execution, therefore, and as seen in other disciplines, as the speed of displacement increases, the time of contact with the floor decreases (especially in the sprint) (Haugen et al. 2015). Speed might be limited by the minimum time necessary to generate the propelling impulse (Weyand, Sandell, Prime $\&$ Bundle, 2010) and by the degree of stiffness of the lower limbs. Millett, Moresi, Watsford, Taylor \& Greene, (2018) showed that stiffer athletes showed lower contact times in sprint test than the control group $(p<.001-.003)$. In a combat sport, Zaggelidis et al. (2012) reported that higher level athletes present lower contact time compared to lower level athletes when executing different vertical jumping tasks $(p<.05-$ $p<.01$ ). In fencing, the control of contact time has been made through the calculation of the RSI (through its components flight time and contact time) and correlation with CODS has been reported $(\mathrm{r}=-.41 ; p<.001)$ (Turner et al. 2016a). Thus, stiffness of the lower body extremities allows the quantification of the interaction between the amount of leg flexion and strength externally applied to the lower extremities (Brughelli \& Cronin, 2008a; Brughelli \& Cronin, 2008b). For this reason, in order to improve the propelling impulse and the speed of the lunge and recoil among sabreurs, it is necessary that these athletes improve their leg stiffness to reduce contact time in technical executions of their movements and the speed of displacement increases.

The present study has limitations that must be recognized. This study used a cross-sectional design that does not allow the establishment of cause and effect relationships. Our sample was only ten subjects, but representative of competitive athletes. Despite these limitations, this study is the first to determine the association between contact time with the hip angle during the lunge and recoil. Therefore, this research can be used by fencing trainers to plan the workouts and reduce the contact time of their athletes.

\section{Conclusion}

In conclusion, the findings obtained in the present study show that the joint position of the lower limbs, specifically the degrees of flexion of the hip joint, evaluated in a novel and low-cost way through taped videos, was inversely related to the lunge attack and recoil contact time among male sabre athletes.

\section{Practical applications}

Given the findings of this study the following practical applications are recommended:

- Practitioners and coaches should introduce in their workouts exercises that increase the level of stiffness of the leg muscles and tendons to decrease the contact time and increase the speed of movement.

- Practitioners and coaches should introduce exercises that increase the level of leg strength in their workouts.

- Practitioners and coaches should introduce in their workouts exercises that increase the level of eccentric strength of the knee extensors to improve the control of movement.

- Practitioners and coaches should prioritize exercises in closed kinetic chain in their workouts.

\section{References}

Aquili, A., Tancredi, V., Triossi, T., De Sanctis, D., Padua, E., D'Arcangelo, G., \& Melchiorri, G. (2013). Performance analysis in saber. Journal of Strength and Conditioning Research, 27(3), 624-630. doi: 10.1519/JSC.0b013e318257803f.

Balsalobre, C., Tejero, C., del Campo, J., \& Bavaresco, N. (2014). The concurrent validity and reliability of a low-cost, highspeed camera-based method for measuring the flight time of vertical jumps. Journal of Strenght and Conditioning Research, 28(2), 528-533. doi: 10.1519/JSC.0b013e318299a52e.

Bottoms, L., Greenhalgh, A., \& Sinclair, J. (2013). Kinematic determinants of weapon velocity during the fencing lunge in experienced épée fencers. Acta of Bioengineering and Biomechanics, 15(4), 109-113. doi: 10.5277/abb130414.

Brughelli, M., \& Cronin, J. (2008a). Influence of running velocity on vertical, leg and joint stiffness: Modeling and recommendations for future research. Sports Medicine, 38(8), 647-657. doi: 10.2165/00007256-200838080-00003.

Brughelli, M., \& Cronin, J. (2008b). A review of research on the mechanical stiffness in running and jumping: Methodology and implications. Scandinavian Journal of Medicine and Science in Sports, 18(4), 417-426. doi: 10.1111/j.1600- 
0838.2008.00769.x.

Brughelli, M., Cronin, J., Levin, G., \& Chaouachi, A. (2008). Understanding change of direction ability in sport: A review of resistance training studies. Sports Medicine, 38(12), 1045-1063. doi: 10.2165/00007256-200838120-00007.

Busquet, L. (2004). Las Cadenas Musculares. Tomo IV. Miembros Inferiores. Barcelona, España: Paidotribo.

Capozzo, A., Catani, F., Croce, U., \& Leardini, A. (1995). Position and orientation in space of bones during movement: anatomical frame definition and determination. Clinical Biomechanics, 10(4), 171-178. doi: 10.1016/0268-0033(95)91394-t.

Chaabene, H. (2017). Change of direction tasks: Does the eccentric muscle contraction really matter? Archives of Sports Medicine 1(1). 1-2. doi: 10.36959/987/222.

Chaabene, H., Prieske, O., Negra, Y., \& Granacher, U. (2018). Change of direction speed: Toward a strength training approach with accentuated eccentric muscle actions. Sports Medicine 48(8), 1773-1779. doi: 10.1007/s40279-018-0907-3.

Clery R. (1965). L'escrime aux trois armes. Paris, Francia: Amphora.

Cronin, J., McNair, P., \& Marshall, R. (2003). Lunge performance and its determinants. Journal of Sports Sciences, 21(1), 49-57. doi: 10.1080/0264041031000070958.

Damsted, C., Nielsen, R., \& Larsen, L. (2015). Reliability of videobased quantification of the knee- and hip angle at foot strike during running. International Journal of Sports Physical Therapy, 10(2), 147-154.

Garhammer, J. (1993). A review of power output studies of olympic and powerlifting: methodology, peformance prediction, and evaluation tests. Journal of Strength and Conditioning Association, 7(2), 76-89.

Gaugler, W. (1992). La scienza della scherma. Bolonia, Italia: Zachinelli.

Gholipour, M., Tabrizi, A., \& Farahmand, F. (2008). Kinematics analysis of lunge fencing using stereophotogrametry. World Journal of Sport Sciences, 1(1), 32-37.

Greenhalgh, A., Bottoms, L., \& Sinclair, J. (2013). Influence of surface on impact shock experienced during a fencing lunge. Journal of Applied Biomechanics, 29(4), 463-467. doi: 10.1123/ jab.29.4.463.

Gresham-Fiegel, C., House, P., \& Zupan, M. (2013). The effect of nonleading foot placement on power and velocity in the fencing lunge. Journal of Strength and Conditioning Research, 27(1), 57-63. doi: 10.1519/JSC.0b013e31824e0e9d.

Gutiérrez, M., Rojas, F., Antonio, R., \& Navarro, E. (2013). Response timing in the lunge and target change in elite versus medium-level fencers. European Journal of Sport Science, 13(4), 364-371. doi: 10.1080/17461391.2011.635704.

Gutiérrez, M., Zingsem, C., Gutiérrez, C., Giles, F., \& Rojas, F. (2014). Effect of uncertainty during the lunge in Fencing. Journal of Sports Science and Medicine, 13(1), 66-72.

Haugen, T., Tonnesen, E., \& Seiler, S. (2015). 9.58 and 10.49: Nearing the citius end for $100 \mathrm{~m}$ ? International Journal of Sports Physiology and Performance, 10(2), 269-272. doi: 10.1123/ijspp.2014-0350.

Iglesias, X. (1997). Valoració funcional específica en l'esgrima. (Doctoral thesis). University of Barcelona, Barcelona. España.

Khademi, K., \& Berenji, S. (2014). The effect of base support stability on shoulder muscle activity during closed kinematic chain exercises. Journal of Bodywork and Movement Therapies, 18(2), 233-238. doi: 10.1016/j.jbmt.2013.08.005.

Kim, M., Kong, B., \& Yoo, K. (2017). Effects of open and closed kinetic-chain exercises on the muscle strength and muscle activity of the ankle joint in young healthy women. The Journal of Physical Therapy Science, 29(11), 1903-1906. doi: 10.1589/ jpts.29.1903.

Kovacs, M., Roetert, E., \& Ellenbecker, T. (2008). Efficient deceleration: the forgotten factor in tennis-specific training. Strength and Conditioning Journal, 30(6), 58-69. doi: 10.1519/ SSC.0b013e31818e $5 \mathrm{fbc}$.

Lee, N., Kwon, J., Son, S., Kang, K., Kim, K., \& Hyun-Nam, S. (2013). The effects of closed and open kinetic chain exercises on lower limb muscle activity and balance in stroke survivors. NeuroRehabilitation, 33(1), 177-183. doi: 10.3233/NRE130943.

López, E. (2008). El tocado con fondo en la esgrima de alto nivel. Estudio biomecánico del fondo en competición. El golpe recto clásico. (Doctoral thesis). Universidad Politécnica, Madrid. España.

McBride, J., Triplett, T., Davie, A., \& Newton, R. (1999). A comparison of strength and power characteristics between power lifters, olympic lifters, and sprinters. Journal of Strength and Conditioning Research, 13(1), 58-66.

Millett, E., Moresi, M., Watsford, M., Taylor, P., \& Greene, D. (2018). Variations in lower body stiffness during sports-specific tasks in well-trained female athletes. Sports Biomechanics, 12, 1-16. doi: 10.1080/14763141.2018.1521466.

Sinclair, J., \& Bottoms, L. (2013). Gender differences in the kinetics and lower extremity kinematics of the fencing lunge. International Journal of Performance Analysis in Sport, 13(2), 440-451. doi: 10.1080/247486688.2013.11868660.

Stensdotter, A., Hodges, P., Mellor, R., Sundelin, G., \& HägerRoss, C. (2003). Quadriceps activation in closed and in open kinetic chain exercise. Medicine and Science in Sports and Exercise, 35(12), 2043-2047. doi: 10.1249/ 01.MSS.0000099107.03704.AE.

Steward, S., \& Kopetka, B. (2005). The kinematic determinants of speed in the fencing lunge. Journal of Sports Sciences, 23(105).

Szabó L. (1977). Fencing and the master. Budapest, Hungría: Corvina.

Thirioux P. (1970). Escrime moderne aux trois armes. París, Francia: Amphora.

Tsolakis, C., \& Vagenas, G. (2010a). Anthropometric, physiological and performance characteristics of elite and sub-elite fencers. Journal of Human Kinetics, 23, 89-95. doi: 10.2478/v10078010-0011-8.

Tsolakis, C., Kostaki, E., \& Vagenas, G. (2010b). Anthropometric, flexibility, strength-power, and sport-specific correlates in elite fencing. Perceptual and Motor Skills, 110(3), 1015-1028. doi: 10.2466/pms.110.C.1015-1028.

Turner, A., Bishop, C., Chavda, S., Edwards, M., Brazier, J., \& Kilduf, L. (2016a). Physical characteristics underpinning lunging and change of direction speed in fencing. Journal of Strength and Conditioning Research, 30(8), 2235-2241. doi: 10.1519/ JSC.0000000000001320.

Turner, A., Marshal, G., Phillips, J., Noto, A., Buttigieg, C., Chavda, S.,... Kilduf, L. (2016b). Physical characteristics underpinning repetitive lunging in fencing. Journal of Strength and Conditioning Research, 30(11), 3134-3139. doi: 10.1519/ JSC.0000000000001402.

Turner, T., James, N., Dimitriou, L., Greenhalgh, A., Moody, J., Fulcher, D.,...Kilduff, L. (2014). Determinants of olympic fencing performance and implications for strength and conditioning training. Journal of Strength and Conditioning Research, 28(10), 3001-3011. doi: 10.1519/ JSC.0000000000000478.

Weyand, P., Sandell, R., Prime, D., \& Bundle, M. (2010). The biological limits to running speed are imposed from the ground up. Journal of Applied Physiology, 108(4), 950-961. doi: 10.1152/japplphysiol.00947.2009.

Zaggelidis, G., Lazaridis, S., Malkogiorgos, A., \& Mavrovouniotis, F. (2012). Differences in vertical jumping performance between untrained males and advanced Greek judokas. Archives of Budo, 8(2), 87-90. doi: 10.12659/AOB.882775. 